\title{
Evaluation of Online Public Opinion Topic and Early Warning of Public Opinion
}

\author{
Ma Junhong \\ Xi'an International University, Xi'an, Shaanxi, China,710077
}

\begin{abstract}
The evaluation system and grading program of online public opinion topic were proposed in the paper via the analysis of the online public opinion topic. The related analysis was made for different public opinion topics, the warning system was proposed, thus exploring new ideas for the healthy development of online public opinion.
\end{abstract}

Keywords: Analysis of online public opinion; Online forum

\section{Introduction}

The topic identification, topic tracking and topic evaluation are mainly included for the analysis of online public opinion. [1] The topic identification and topic tracking are the key for the analysis of public opinion, while the topic evaluation and public opinion warning are the ultimate goals. There have been many scholars researching the online public opinion information collection, information preprocessing,[2] topic identification and topic tracking technology, while the above technological researches are conducted to evaluate and have the early warning on the online public opinion topic. [3] The evaluation technology for the online public opinion topic is focused on the chapter.

\section{Evaluation process for online public opinion topic}

A reasonable evaluation process is the guarantee for the effective evaluation, and the evaluation process for the online public opinion topic can be described as follows:

The public opinion topic evaluation index system composed by some interrelated indexes shall be built. The index in the index system is the evaluation basis and standard determined to evaluate certain research object, including the index name and index value. The index is the basis to evaluate the public opinion topic among the evaluation of online public opinion topic, and the determination of index item will directly influence the accuracy and comprehensiveness of evaluation result.

The weight of evaluation index which is the quantized value of the importance of index shall be determined. The allocation of each index weight will directly influence the evaluation result of the topic, therefore, a suitable method is needed to determine the weight of featured index of the topic. The weight of each index is obtained via the analytic hierarchy process combined with the qualitative and quantitative analysis.

The quantization of index value shall be evaluated. The featured index value of the topic shall be obtained via IP localization, WEB search, statistical analysis and other methods before unifying the dimension evaluation, while the unit of measurement among each index value is inconsistent with the order of magnitude, therefore, the unified process of index dimension shall be conducted before the comprehensive processing. The dimensionless method is used to quantify the evaluation index value and unify the dimension to realize the comprehensive calculation of evaluation value. 
The public opinion topic shall be evaluated comprehensively, the topic evaluation value is obtained via the method of weighted mean, the index weight matrix and index quantized value matrix are calculated comprehensively, and the public opinion topic evaluation value is obtained. The early warning level is determined according to the evaluation value, and the corresponding warning operation is realized.

\section{Build the evaluation index system}

Based on the existing online public opinion safety evaluation index system in our country and the statistics on the previous topics, the paper builds the online public opinion topic evaluation index system from five dimensions of quantity, time, attention, opinion and concentration as shown in Table 1.

Table 1 Online public opinion topic evaluation index system

\begin{tabular}{|c|c|c|}
\hline First layer & Second layer & Third layer \\
\hline \multirow[t]{3}{*}{ Quantity dimension } & \multirow[t]{3}{*}{ Post quantity } & Total posts \\
\hline & & Growth rate of post quantity \\
\hline & & Average daily post quantity \\
\hline \multirow[t]{2}{*}{ Time dimension } & \multirow[t]{2}{*}{ Survival time of topic } & Survival time of single topic \\
\hline & & Survival time of expanded topic \\
\hline \multirow[t]{8}{*}{ Netizen's attention } & \multirow[t]{2}{*}{ Click } & Click volume \\
\hline & & Click rate \\
\hline & \multirow[t]{2}{*}{ Comment } & Comment volume \\
\hline & & Comment rate \\
\hline & \multirow[t]{2}{*}{ Reprint } & Reprint volume \\
\hline & & Reprint rate \\
\hline & \multirow[t]{2}{*}{ Citation } & Citation volume \\
\hline & & Citation rate \\
\hline \multirow[t]{2}{*}{ Opinion dimension } & \multirow[t]{2}{*}{ Opinion content } & Opinion tendentiousness \\
\hline & & Opinion sensitivity \\
\hline \multirow[t]{2}{*}{ Concentration dimension } & \multirow[t]{2}{*}{ Netizen's concentration } & Territory concentration \\
\hline & & Industrial concentration \\
\hline
\end{tabular}

Seen from Table 1, there are three layers for online public opinion topic evaluation index system. The first-level index system mainly starts from five dimensions of quantity, time, attention, opinion and concentration. The quantity dimension includes the total post quantity and quantity change rate and others related with the topic; the time dimension refers to the survival time of the topic; the netizen's attention reflects the concerned degree of the topic from the netizen's click and comment and others; the opinion dimension reflects the netizen's attitude and topic opinion sensitivity from two aspects of opinion tendency and opinion sensitivity; the concentration dimension states the wide range of topic communication via the territory concentration and industrial concentration. The detailed description on the second-level and third-level index is as follows:

Quantity dimension: the post quantity mainly describes the topic feature from the total quantity and quantity change and others. It includes specifically the total main posts related with the topic in the whole community website, the growth rate (generally in days) of post within the unit time, and average quantity of each post. The quantity ratio is the ratio for the topic-related post on the total posts in the station. Usually, the topic evaluation value is higher when the total posts of the topic increase, the growth rate complies with the general rule of topic communication (especially at the public opinion development stage), average post item in certain period of time is increased, and the ratio of the topic-related post on the total posts in the station is increased.

Time dimension: the time dimension is the survival time of the topic, which is the time difference of the whole life cycle from the occurrence of the topic to the final death, including the single topic survival time and expanded topic survival time. The leveled multiple center topic has been defined 
in Chapter III, the expanded topic is another subclass topic belonging to the same parent class topic, it is related with the topic while not belonging to the topic event.

Netizen's attention: it mainly starts from four aspects: click, comment, reprint and citation. Each action feature includes the quantity feature and the change rate of the action feature along with the unit time respectively. The click feature of a topic can include the total click volume and rate of the topic within the existing survival time. Similarly, the comment includes the total comment volume and rate of all posts of the topic, so are the reprint and citation.

Opinion dimension: it is mainly reflected on the opinion content, including the citizen's opinion tendency and sensitivity. The opinion tendency can be divided into the positive, negative and neutral, and the evaluation value is higher when the topic opinion tends to two poles obviously. The opinion sensitivity is divided into five levels, and it can be judged via the sensitive words contained in the opinion content. The higher the opinion sensitivity, the higher the topic evaluation value.

Concentration dimension: it mainly includes the territory concentration and industrial concentration, which concerns the geographical location and industrial distribution of the netizen concerning the topic. The more dispersed citizen's territory distribution and industrial distribution, the huger influence of the topic, and the higher the evaluation value.

\section{Online public opinion warning system}

The reasonable and mature public opinion warning system shall be built firstly to achieve the favorable warning effect on the online public opinion. The so-called warning system refers to gathering group consisting all factors of complete warning activity, including the sum of warning index, level, measurement, method and activity and other factors. Combined with the international standard and the provision in the related agency management in our country, the paper divides the warning level of online public opinion into five levels: first-level (abnormal, blue warning), second-level (warning level, green warning), third-level (risk level, yellow warning), fourth-level (severe danger level, orange warning), fifth-level (extreme danger level, red warning). The online public opinion warning level is divided as shown in Table 2.

Table 2 Classification table of online public opinion warning level

\begin{tabular}{|l|l|l|l|l|l|}
\hline Warning level & 5 & 4 & 3 & 2 & 1 \\
\hline Warning level & $\begin{array}{l}\text { Extreme } \\
\text { danger level }\end{array}$ & $\begin{array}{l}\text { Severe danger } \\
\text { level }\end{array}$ & Risk level & Warning level & Abnormal \\
\hline $\begin{array}{l}\text { Topic } \\
\text { evaluation } \\
\text { value }\end{array}$ & {$[9,10]$} & {$[8,9]$} & {$[7,8]$} & {$[6,7]$} & {$[5,6]$} \\
\hline Warning sign & Red & Orange & Yellow & Green & Blue \\
\hline Description & $\begin{array}{l}\text { Extreme high } \\
\text { popularity, } \\
\text { very sensitive } \\
\text { topic, } \\
\text { controversial, } \\
\text { and powerful } \\
\text { provocation }\end{array}$ & $\begin{array}{l}\text { High } \\
\text { popularity, } \\
\text { sensitive topic, } \\
\text { controversial, } \\
\text { and certain } \\
\text { provocation }\end{array}$ & $\begin{array}{l}\text { High } \\
\text { popularity, } \\
\text { insensitive, } \\
\text { have the } \\
\text { dispute }\end{array}$ & $\begin{array}{l}\text { Common } \\
\text { popularity, } \\
\text { insensitive } \\
\text { topic, slightly } \\
\text { high attention }\end{array}$ & $\begin{array}{l}\text { Low } \\
\text { popularity, } \\
\text { insensitive } \\
\text { topic, } \\
\text { concerned }\end{array}$ \\
\hline $\begin{array}{l}\text { Emergency } \\
\text { measure }\end{array}$ & $\begin{array}{l}\text { Spread to the } \\
\text { related } \\
\text { department } \\
\text { and the party } \\
\text { rapidly, and } \\
\text { process } \\
\text { immediately }\end{array}$ & $\begin{array}{l}\text { Timely spread } \\
\text { to the related } \\
\text { department, } \\
\text { and exercise } \\
\text { discretion in } \\
\text { light of the } \\
\text { circumstances }\end{array}$ & $\begin{array}{l}\text { Spread to the } \\
\text { related } \\
\text { department, } \\
\text { and be noted }\end{array}$ & $\begin{array}{l}\text { Spread to the } \\
\text { related } \\
\text { department, } \\
\text { and be noted }\end{array}$ & $\begin{array}{l}\text { Ignore without } \\
\text { processing }\end{array}$ \\
\hline
\end{tabular}

Usually, the more posts related with the topic, the higher the netizen's attention, the longer the survival time of the topic, the higher the opinion's sensitivity, two-pole distribution of opinion and 
attitude in the majority of negative attitude, the more dispersed regional and industrial distribution, the higher the evaluation value of the public opinion topic, and the higher the corresponding early warning level. It may cause certain loss for the society if it is the negative topic. Therefore, we shall note and take the corresponding measures for such kind of topic.

\section{Conclusion}

Currently, the Internet has become one of important channels for the production and development of public opinion, while some negative public opinion information may cause certain damage on the society. Therefore, it is necessary to analyze and guide correctly the online public opinion information. A kind of public opinion topic evaluation method based on the analytic hierarchy method is proposed, the online public opinion topic evaluation index system is built, the evaluation index is quantized, and the online public opinion warning system is built in the paper.

\section{Acknowledgements}

The author acknowledges the project of the "13th Five-Year Plan" for education science in Shaanxi,China(Grant:SGH16H271).

\section{References}

[1] Tan, Pham Ngoc, Tran Cong Luc, and Nguyen Trung Minh. "Design and Research on High-Speed Ethernet Information Module." Journal of Applied Science and Engineering Innovation 4.3 (2017): 68-71.

[2] Chen, Xue Gang, Sheng Duan, and Lu - da Wang. "Research on trend prediction and evaluation of network public opinion."Concurrency and Computation: Practice and Experience 29.24 (2017).

[3] Hui, J. I. N. "Application Discussion of Cloud Computing in Hospital Information Construction." Journal of Applied Science and Engineering Innovation 4.4 (2017): 144-147. 